RGSA - Revista de Gestão Social e Ambiental

\title{
AVALIAÇÃO E ALTERNATIVAS DE MINIMIZAÇÃO DO USO DE ÁGUA EM UMA INDÚSTRIA DE REFRIGERANTES
}

\author{
Carla Eloísa Diniz dos Santos \\ Graduanda em Engenharia Ambiental da Universidade Estadual Paulista Júlio de Mesquita Filho - UNESP \\ c.diniz@ymail.com
}

Maria Cristina Rizk

Doutora em Engenharia Química pela Universidade Estadual de Maringá - UEM

Professora assistente do curso em Engenharia Ambiental da Universidade Estadual Paulista Júlio de Mesquita Filho - UNESP

crisrizk@fct.unesp.br

Ana Paula D'Avoglio

Engenheira Ambiental da Universidade Estadual Paulista Júlio de Mesquita Filho - UNESP anadavoglio@yahoo.com.br

Leandro Cesar Neves Lima

Engenheiro Ambiental da Universidade Estadual Paulista Júlio de Mesquita Filho - UNESP leandrocesarlima@yahoo.com.br

\section{RESUMO}

A crescente preocupação das empresas com a preservação ambiental manifesta-se pela adoção de um Sistema de Gestão Ambiental (SGA), que estimula o melhoramento contínuo em questões que envolvam o meio ambiente. Neste trabalho, procurou-se fazer um levantamento completo do volume de água utilizado nas atividades de uma indústria de refrigerantes, localizada no interior do estado de São Paulo, Brasil. A partir dos dados obtidos, formulou-se uma expressão de indicativo ambiental (IA), que expressa a eficiência dos processos produtivos em relação à água e indica também, de forma secundária, o desempenho ambiental da empresa perante este recurso natural. Como resultado, observou-se que a indústria em questão apresentou um valor de IA de 2,165; que está acima do esperado para indústrias do setor. Então, foram propostas algumas medidas de minimização no uso de água, para que esta empresa desenvolva suas atividades de forma a garantir a qualidade e disponibilidade de recursos às gerações futuras.

Palavras-chave: Impacto ambiental; Recursos hídricos; Sistema de gestão ambiental.

\section{EVALUATION OF ALTERNATIVES AND MINIMIZING THE USE OF WATER IN A SOFT DRINK INDUSTRY}

\begin{abstract}
The growing concern for companies related to environmental preservation is the importance of adapting to new social trends to survive in a market becoming increasingly competitive. An organization can promise a better environmental performance starting with the adoption of an Environmental Management System (EMS) to continuously improve matters related to the environment. This study was done using a complete survey of the water used in activities conducted in a daily soft drink industry located in the state of São Paulo, Brazil. The data obtained led to the creation of an environmental index expression (IA) which represents the efficiency of productive processes in relation to the water and secondarily indicates the environmental performance of the company in relation to this natural resource. It was observed that the IA of the studied industry was 2.165, a superior value to the industries of the same segment that develop more sustainable activities. Measures have been proposed to minimize the water use in order for this company to develop its activities efficiently and above all protect the environment and ensure the quality and availability of resources for future generations.
\end{abstract}

Keywords: Environmental management system; Soft drink industry; Minimization; Water. 


\section{INTRODUÇÃO}

Ao longo da história, o homem sempre utilizou os recursos naturais do planeta e gerou resíduos com baixíssimo nível de preocupação. Os recursos eram abundantes e a natureza aceitava sem reclamar os despejos, porém, no último século, a relação do homem com o meio ambiente foi significativamente alterada pelo crescimento populacional da espécie humana, combinado com o grande desenvolvimento tecnológico e industrial, desencadeando inúmeros fatores que geraram danos que o meio ambiente não foi capaz de assimilar, causando incalculáveis impactos ambientais (Moura, 2002). A necessidade de uma relação sustentável entre a produção de bens de consumo e o meio ambiente vem sendo um fator determinante para a manutenção das empresas no mercado atual.

Em 1991, foi criada a "Carta Empresarial para o Desenvolvimento Sustentável” com o objetivo de ajudar organizações em todo o mundo a melhorar os resultados de suas ações sobre o ambiente (Andrade, Tachizawa \& Carvalho, 2002), surgindo assim, a ideia de gestão ambiental nas empresas.

Como observa Moura (2002), empresas que visam garantir a qualidade ambiental, além de conquistarem a satisfação dos clientes, ainda melhoram sua imagem; conquistam novos mercados; reduzem custos pela eliminação de desperdícios; melhoram seu desempenho com o aumento da produtividade; reduzem riscos evitando pagamentos de multas; aumentam a permanência do produto no mercado, por não ocorrerem reações negativas dos consumidores; têm mais facilidade de obter financiamentos e certificados.

Segundo a NBR ISO 14.001 (2004), um Sistema de Gestão Ambiental (SGA) é “[...]parte de um sistema de gestão de uma organização, utilizada para desenvolver e implementar sua política ambiental e para gerenciar seus aspectos ambientais", permitindo assim avaliar e controlar os impactos de suas atividades, produtos e serviços.

Qualquer programa de melhoria ou de mudanças culturais em uma organização deve ser feito por meio de um planejamento estratégico de longo prazo, em que sejam definidos os objetivos, as metas, os programas e atividades, lembrando que gestão ambiental não pode ser tratada isoladamente, já que esta faz parte da gestão pela qualidade total de uma empresa (Viterbo Júnior, 1998), definida, em alguns casos, como Sistema Integrado de Gestão Ambiental.

Ainda, segundo Viterbo Júnior (1998), um importante instrumento do SGA é o balanço de massa ou ecobalanço, que consiste em um balanço entre os insumos que entram e os produtos que saem, considerando o rendimento padrão do processo. O balanço de massa também permite ter uma ideia inicial da significância dos aspectos ambientais relevantes para a organização e seus potenciais impactos relativos, pois a diferença no balanço será composta de resíduos sólidos, líquidos e gasosos (Viterbo Júnior, 1998).

A partir deste parâmetro podem-se construir então indicadores ambientais que expressam, em relação à uma unidade de produção, a eficiência (ou ecoeficiência) ambiental e produtiva em uma organização.

Segundo Moura (2002), outro instrumento importante que pode resumir toda a implantação do processo de SGA, que também está estabelecido na NBR ISO 14.001(2004) é o ciclo PDCA, composto por quatro passos: planejar (Plan), realizar (Do), verificar (Check) e atuar para corrigir (Action), lembrando que este ciclo é baseado no conceito de melhoramento contínuo. Ainda, em um SGA, o ciclo PDCA deve ser precedido pelo estabelecimento da Política Ambiental da organização.

Quanto às indústrias de refrigerantes, pode-se afirmar que a implantação de um SGA é de suma importância, já que nestas empresas consomem-se enormes quantidades de água e ainda, gerase um grande fluxo de efluentes líquidos e resíduos sólidos. Desse modo, busca-se com a adoção de um SGA, atender os requisitos exigidos para garantir a qualidade ambiental, bem como a minimização de resíduos gerados nas atividades produtivas. 
Dados da Associação dos Fabricantes de Bebidas do Brasil (Afrebras, 2009) indicam que as primeiras indústrias brasileiras de refrigerante surgiram no início do século 20 e que atualmente existem 238 empresas em atividade, sendo a maioria localizada no sudoeste do país. Na região, estão instaladas pequenas e médias empresas e ainda três grandes organizações (Ambev, Coca-Cola e Schincariol), que sozinhas detêm $80 \%$ da participação do setor no mercado.

Outro dado relevante é que o Brasil consome cerca de 11,9 bilhões de litros de refrigerante por ano (2002), ficando em terceiro lugar no ranking mundial em venda de refrigerantes, atrás dos EUA e do México (Abir, 2002 apud Campos e Oliveira, 2004).

Considerando os aspectos ambientais, de acordo com dados da Organização NãoGovernamental Cempre (2008), para a produção de 1 litro de refrigerante são gastos, em média, cerca de 2 litros de água. Portanto, pode-se dizer que, em um ano, o consumo médio de água para produção de refrigerante é de quase 24 bilhões de litros de água. Assim, o setor de bebidas é apontado como um dos maiores setores em potencial para implantação de um sistema de gestão ambiental (Senai apud Xavier, 2003).

Esses dados variam de acordo com as características das empresas, uma vez que existem algumas indústrias que vêm investindo cada vez mais na área ambiental, como, por exemplo, algumas fábricas da Companhia Coca-Cola, que em 2004 já apresentavam um consumo de água na faixa de 1,3 litros para cada litro de bebida, pretendendo reduzir esta faixa ainda mais. Segundo dados da Companhia, a forma de economia que ainda resta investir está na captação da água da chuva, por exemplo, para limpeza de piso e em sanitários (Abir, 2009)

Nesse sentido, este trabalho tem como objetivo avaliar o consumo de água em todo o processo produtivo de uma empresa de refrigerantes e, assim, construir cenários visando à redução da utilização deste recurso.

\section{MÉTODO DE PESQUISA}

Este estudo foi desenvolvido em uma indústria de refrigerantes de médio porte, localizada no estado de São Paulo, cujo processo produtivo abrange todas as etapas da produção de refrigerante, desde o preparo do xarope simples (base do refrigerante) até o envase e distribuição do produto final. Para a produção, são empregadas quantidades significativas de água, açúcar, gás carbônico para carbonatação, além de alguns aditivos, como conservantes, estabilizantes, acidulantes, corantes e essências.

A produção do refrigerante é dividida, resumidamente, em três etapas: preparo do xarope simples, do xarope composto e fabricação do refrigerante, realizadas em diferentes setores dentro da indústria.

Para o desenvolvimento do trabalho, inicialmente, foi feito um levantamento de informações para a realização de um diagnóstico da situação ambiental de cada setor da empresa. Para isso, foram realizados diversos acompanhamentos no setor produtivo, consultas bibliográficas e conversas com técnicos responsáveis. As informações obtidas permitiram avaliar o funcionamento e consumo de água dos reservatórios e demais sistemas produtivos.

\subsection{Avaliação do consumo de água para as diferentes etapas do processo produtivo na indústria}

A estimativa do consumo de água nas etapas do processo produtivo foi realizada com base em determinações das vazões médias dos pontos de fornecimento de água (mangueiras, registros, entre outros). Estes pontos estão dispostos, principalmente, na sala de xarope simples, na sala de xarope composto e nas linhas de produção 40, 70 e 72 (diferenciadas apenas por suas capacidades de produção e pelo tipo de garrafa utilizada no envase). 
Além desta estimativa das vazões médias, foram feitas medições pontuais do consumo de água nas diferentes unidades responsáveis pelo processo produtivo (área de armazenagem e despejo de açúcar; sala onde é produzido o xarope simples; sala onde é obtido o xarope composto e as áreas de envase do refrigerante, nas quais há consumo de água por parte da máquina Flo-mix, máquina enchedora, máquina tampadora, rotuladoras e esteiras). Foi contabilizada também a água demandada na limpeza destes locais.

Tais dados auxiliaram na avaliação do uso do recurso hídrico nas etapas do processo de fabricação de refrigerante, bem como na adoção de políticas de consumo de água e determinação de objetivos e metas no sistema de gestão ambiental, visando a minimização do consumo de água.

O consumo de água foi estimado considerando-se: a limpeza diária, que ocorre ao final do expediente; a limpeza na troca de produto, que ocorre sempre que o sabor ou tipo de produto destinado para o envase é diferente; e a limpeza completa de final de semana, que é feita com o uso de produtos químicos para a assepsia total das máquinas, tubulações, esteiras e demais componentes do processo produtivo. Considerou-se também a limpeza realizada nas unidades auxiliares de produção, tais como filtros de abrandamento de água dos poços e lavadoras de recipientes de vidro para o envase do produto final.

Estas vazões médias foram estimadas a partir de cálculos de intervalo de tempo que cada um dos pontos de fornecimento levava para preencher determinados volumes, estabelecendo, assim, um tempo médio para cada ponto. Calculado o tempo médio e sabendo o volume preenchido, foi estimada a vazão média para os pontos de fornecimento de água. A partir do tempo de uso cronometrado para cada atividade, estimou-se o volume de água consumido. Estabeleceu-se também uma produção média de refrigerante, correspondendo a um período no qual são englobados todos os processos de limpeza.

Assim, para o cálculo do balanço de massa para o recurso hídrico, como mostrado na Figura 1, estabeleceram-se procedimentos práticos para a obtenção do volume de água consumido na entrada (processos de limpeza e produção), bem como os volumes de saída (produto final e efluente gerado). Desta forma, pôde-se estimar a vazão média de geração de efluente e compará-la com estudos anteriores.

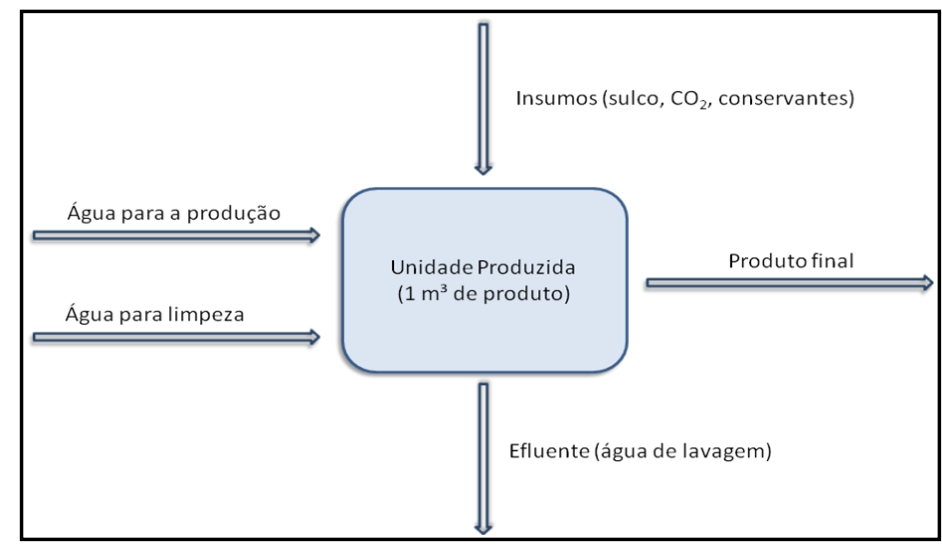

Figura 1: Balanço de massa para o recurso hídrico

Fonte: Dados da Pesquisa

A partir do balanço de massa, foi possível elaborar um Indicador Ambiental (IA), que expressa a eficiência dos processos produtivos em relação à água e indica também, de forma secundária, o desempenho ambiental da empresa perante este recurso natural. Sua fórmula é representada pela Equação 1

$$
\begin{gathered}
\mathrm{IA}=\frac{\text { volume de água no produto }+ \text { volume da água de limpeza }}{\text { volume de produto produzido }} \\
\text { Equação } 1
\end{gathered}
$$


Vale observar que, no numerador, o valor associado a "volume de água no produto" é constante visto que qualquer alteração implica em prejuízos nas características do produto.

\subsection{Estimativa da produção média de refrigerante}

Realizadas as estimativas pontuais de consumo de água é necessário saber qual a produção média de refrigerante em um período especificado, para que se saiba a frequência com que os procedimentos de limpeza são realizados. Esta produção média especifica quantos tachos de xarope simples são produzidos, quantos tanques de xarope compostos são utilizados e, deste xarope produzido, quanto de produto final (refrigerante) é destinado para cada linha (70, 40 e 42). Além disso, a produção média também indica os sabores produzidos para se estimar qual a frequência da troca de sabor, além da quantidade de recipientes de envase utilizados e o número de horas de funcionamento das lavadoras.

Para a estimativa de consumo de água será considerado o período de 2 semanas, equivalente a 12 dias (de segunda a sábado), totalizando 88 horas de trabalho. Este período abrange todos os processos de limpeza realizados, permitindo assim, uma estimativa mais precisa de consumo de água.

\section{RESULTADOS E DISCUSSÕES}

\subsection{Avaliação do consumo de água para as diferentes etapas do processo dentro da indústria}

A Figura 2 expressa resumidamente todo o consumo de água estimado para cada um dos setores produtivos, considerando os processos de limpeza diários, de final de semana e de troca de sabor. Observa-se que o maior consumo ocorre nas limpezas realizadas nos finais de semana, por serem mais profundas e que os processos de limpeza para troca de sabor apenas ocorrem nas enchedoras de cada uma das linhas, não havendo, portanto, este tipo de limpeza nos demais setores.

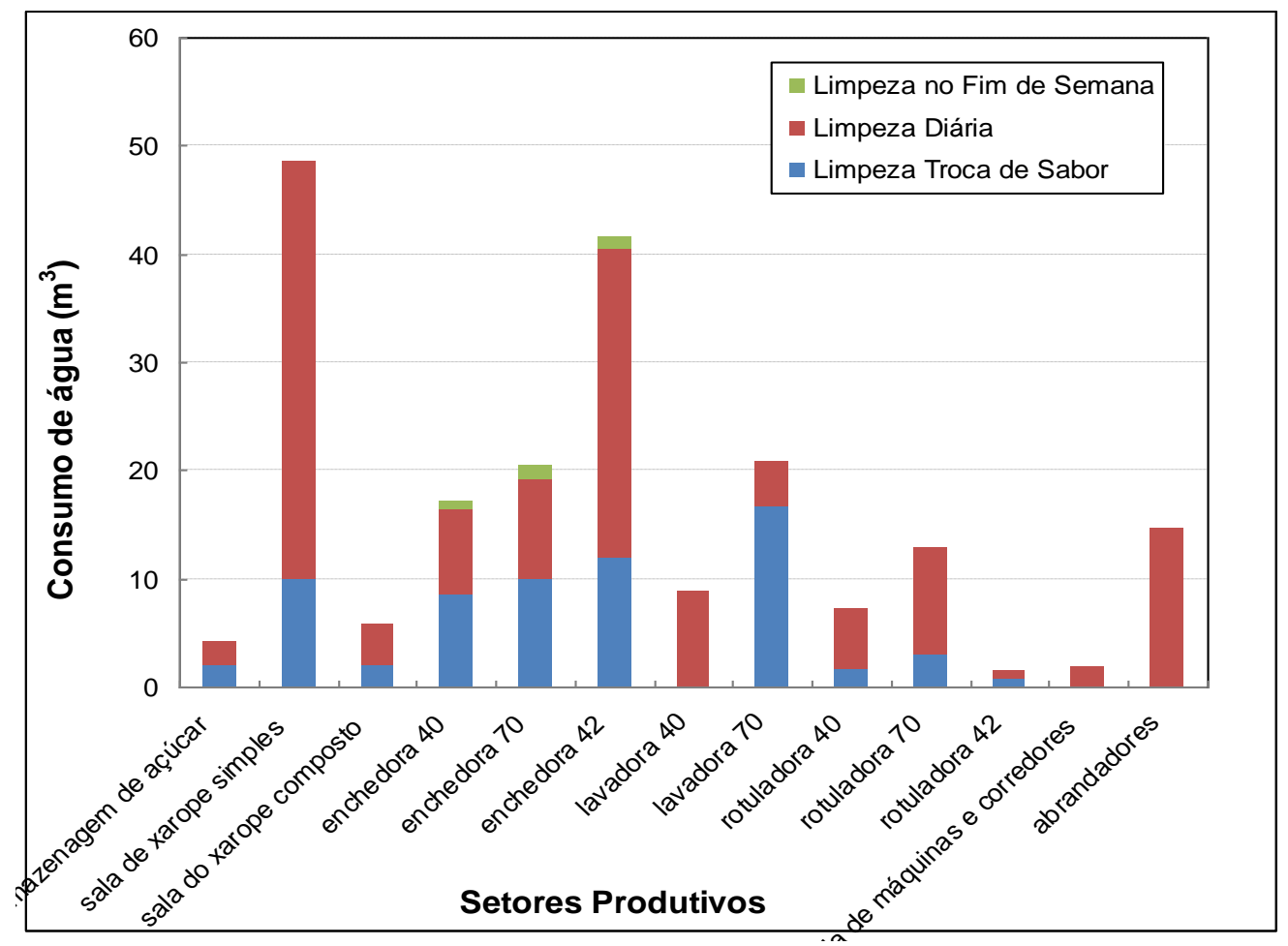

Figura 2: Síntese do consumo de água pontual associado aos procedimentos de limpeza.

Fonte: Dados da pesquisa 
Deve-se ressaltar que a lavadora 40 não passa por processo de limpeza diário, e que na lavadora 42 não é registrado um consumo considerável de água, por isso a informação do consumo de água foi omitida no gráfico. Ainda, percebe-se que a sala de xarope simples representa a maior demanda de água para o processo de limpeza de final de semana, pelo fato de ela garantir a qualidade do produto, a ausência de microrganismos infectantes no tacho de cozimento, no tanque de pré-capa e, principalmente, nas tubulações do equipamento de filtragem, o que acarreta na execução de um complexo processo de limpeza não só dos equipamentos envolvidos, como também das paredes e teto da sala e de toda a área do entorno da xaroparia.

\subsection{Cálculo da produção média de efluente e do consumo total de água}

$\mathrm{Na}$ tabela 2, são especificados os setores produtivos analisados e também o volume de efluente gerado em cada um, relativo ao período de 12 dias de funcionamento da indústria, considerando a limpeza diária, a limpeza na troca de sabor e, por fim, a limpeza de final de semana. Como resultado, tem-se que, em 12 dias, utiliza-se 2054,23 $\mathrm{m}^{3}$ de água em todo o processo de fabricação do refrigerante.

Tabela 2: Volume total de efluente gerado por setor.

\begin{tabular}{|c|c|}
\hline Setor & Consumo de água no período $\mathbf{~ ( m}^{\mathbf{3}}$ ) \\
\hline Área de armazenagem de açúcar & 23,90 \\
\hline Sala de xarope simples & 172,72 \\
\hline Sala de xarope composto & 68,21 \\
\hline Enchedora 70* & 133,31 \\
\hline Enchedora 40 & 110,26 \\
\hline Enchedora 42* & 244,64 \\
\hline Lavadora 70* & 734,58 \\
\hline Lavadora 40** & 79,76 \\
\hline Lavadora 42 & 286,88 \\
\hline Rotuladora, Encaixadora ,Esteiras da linha 70 & 48,56 \\
\hline Rotuladora, Encaixadora, Esteiras da linha 40 & 27,80 \\
\hline Rotuladora, Encaixadora, Esteiras da linha 42 & 9,00 \\
\hline Tanques de diluição de produtos & 23,73 \\
\hline Corredor e sala de máquinas & 3,58 \\
\hline Filtros de abrandamento & 87,30 \\
\hline Total (m & $\mathbf{2 . 0 5 4 , 2 3}$ \\
\hline
\end{tabular}

Fonte: Dados da pesquisa

Notas: (*) considerando o uso do "chuveirinho". (**) somado com o volume de efluente gerado no processo de limpeza.

Calculando-se a vazão média para o período, tem-se que: $2.054,23 \mathrm{~m}^{3} / 88$ horas $(12$ dias $)=$ $23,34 \mathrm{~m} 3 / \mathrm{h}$ que é a vazão média do efluente industrial gerado.

\subsection{Obtenção do valor do IA}

A relação entre o volume de água consumido nos processos de limpeza e o de produto final produzido pode ser facilmente calculada, considerando que o somatório de água no processo de limpeza geral foi igual a $2.054,23 \mathrm{~m}^{3}$ e o volume total de refrigerante produzido foi $1653,00 \mathrm{~m}^{3} \mathbf{e}$ que resultou em uma relação de: $2.054,23 \mathrm{~m}^{3} / 1653,00 \mathrm{~m}^{3}=1,243 \mathrm{~m}^{3}$ de água utilizada nos processos de limpeza para cada $1 \mathrm{~m}^{3}$ de produto final. 
Para obter o valor do indicativo ambiental (IA), calculou-se previamente o volume de água incorporado ao produto final. A tabela 3 traz a relação entre o produto, intermediário ou final, e o respectivo volume de água nele incorporado.

Tabela 3: Relação entre produto final e intermediário e volume de água incorporado.

\begin{tabular}{|c|c|c|c|}
\hline Produto* & $\begin{array}{c}\text { Volume total do } \\
\text { produto }\left(\mathbf{m}^{\mathbf{3}}\right)\end{array}$ & $\begin{array}{c}\text { Proporção em água } \\
(\mathbf{\%})\end{array}$ & $\begin{array}{c}\text { Volume de água } \\
\text { incorporado } \\
\left(\mathbf{m}^{\mathbf{3}}\right)\end{array}$ \\
\hline xarope simples & 257,48 & 50,00 & 128,74 \\
\hline xarope composto & 275,50 & 53,27 & 146,76 \\
\hline Refrigerante & $1.653,00$ & 92,21 & $\mathbf{1 . 5 2 4 , 2 3}$ \\
\hline
\end{tabular}

Fonte: Dados da pesquisa

Nota: $(*)$ intermediário ou final.

Assim, como mostra a tabela acima, para produzir $1.653 \mathrm{~m}^{3}$ de refrigerante num período de 12 dias, $1.524,23 \mathrm{~m}^{3}$ de água são incorporados ao produto. Então, ao volume total de efluente gerado nas operações de limpeza, soma-se o volume de água incorporado ao produto, resultando em uma relação de litros de água consumidos para produzir 1 litro de refrigerante (tabela 4).

Tabela 4: Relação água utilizada para cada unidade de volume de produto

\begin{tabular}{|c|c|c|c|}
\hline $\begin{array}{c}\text { Efluente gerado na } \\
\text { limpeza }\left(\mathbf{m}^{\mathbf{3}}\right)\end{array}$ & $\begin{array}{c}\text { Água incorporada } \\
\text { ao produto }\left(\mathbf{m}^{\mathbf{3}}\right)\end{array}$ & $\begin{array}{c}\text { Volume total de } \\
\text { água utilizada }\left(\mathbf{m}^{\mathbf{3}}\right)\end{array}$ & $\begin{array}{c}\text { Relação } \\
\text { água/produto final }\end{array}$ \\
\hline $2.054,23$ & $1.524,23$ & $3.578,46$ & $\mathbf{2 , 1 6 5}$ \\
\hline
\end{tabular}

Fonte: Dados da pesquisa

Aqui, nota-se que, para cada litro de refrigerante produzido, consomem-se em média 2,165 litros de água, considerando a água utilizada nos processos de limpeza e a água incorporada ao produto. Observa-se, assim, que este valor é superior ao consumido por algumas indústrias de refrigerante, que utilizam em média 1,3 litros de água, como mostram os dados apresentados no site do Instituto Coca-Cola (2009) e também no site da Associação Brasileira das Indústrias de Refrigerantes e Bebidas não-alcoólicas (2009).

\subsection{Elaboração de propostas}

Considerando que a exploração dos recursos hídricos, bem como a geração de efluentes líquidos são um dos aspectos ambientais mais relevantes no cotidiano da empresa, apresentam-se, a seguir, propostas de redução e reuso dos recursos hídricos. Essas propostas têm como intuito auxiliar na elaboração de cenários, com base no diagnóstico ambiental de consumo de água, visando ao cumprimento de metas e objetivos que possam ser estipulados pela empresa.

\section{- Cenário 1: Redução do consumo de água nas operações de limpeza nos pontos de fornecimento de água}

Durante as estimativas de consumo analisou-se também o desperdício médio nas operações de limpeza, diferenciando o volume de água realmente utilizada e as perdas no processo, como mostra a tabela 5:

Tabela 5: Taxa de desperdício para os pontos de fornecimento de água. 
Avaliação e alternativas de minimização do uso de água em uma indústria de refrigerantes

\begin{tabular}{|c|c|c|c|}
\hline Setor & Consumo total $\left(\mathbf{m}^{\mathbf{3}}\right)$ & $\begin{array}{c}\text { Volume } \\
\text { desperdiçado }\left(\mathbf{m}^{\mathbf{3}}\right)\end{array}$ & $\begin{array}{c}\text { Taxa de desperdício } \\
(\mathbf{\%})\end{array}$ \\
\hline Enchedora 40 & 2,29 & 0,25 & 10,90 \\
\hline Enchedora 42 & 7,19 & 2,47 & 34,36 \\
\hline Lavadora 70 & 1,62 & 0,41 & 25,00 \\
\hline Rotuladora 70 & 2,99 & 0,99 & 33,00 \\
\hline Sala de máquinas & 1,79 & 1,08 & 60,6 \\
\hline Taxa média (\%) & & & $\mathbf{3 2 , 7 7}$ \\
\hline
\end{tabular}

Fonte: Dados da pesquisa

Convertendo-se então esta taxa média de desperdício de $32,77 \%$ em redução de consumo do recurso hídrico, pode-se projetar uma série de reduções pontuais de consumo, que contribuirão para uma redução geral no uso da água nas atividades produtivas listadas, como mostra a tabela 6.

Tabela 6: Projeção de redução de consumo para os setores produtivos.

\begin{tabular}{|c|c|c|c|c|}
\hline Setor & $\begin{array}{c}\text { Consumo } \\
\left(\mathbf{m}^{\mathbf{3}}\right)\end{array}$ & $\begin{array}{c}\text { Consumo } \\
\text { pontual }\left(\mathbf{m}^{\mathbf{3}}\right)^{*}\end{array}$ & $\begin{array}{c}\text { Cons. Pontual } \\
\mathbf{c o m} \text { redução }\left(\mathbf{m}^{\mathbf{3}}\right)\end{array}$ & $\begin{array}{c}\text { Consumo com } \\
\text { redução }\left(\mathbf{m}^{\mathbf{3}}\right)\end{array}$ \\
\hline Armaz. açúcar & 23,90 & 23,90 & 16,07 & 16,07 \\
\hline Xarope simples & 172,72 & 77,02 & 51,78 & 147,48 \\
\hline Xarope composto & 68,21 & 14,95 & 10,05 & 63,31 \\
\hline Enchedora 70 & 133,31 & 5,51 & 3,70 & 131,50 \\
\hline Enchedora 40 & 110,26 & 5,30 & 3,56 & 108,52 \\
\hline Enchedora 42 & 244,64 & 15,58 & 10,47 & 239,53 \\
\hline Lavadora 70 & 734,58 & 45,32 & 30,47 & 719,73 \\
\hline Lavadora 40 & 79,76 & 6,98 & 4,69 & 77,47 \\
\hline Lavadora 42** & 286,88 & --- & --- & 286,88 \\
\hline Rotuladora 70 & 48,56 & 48,56 & 32,65 & 32,65 \\
\hline Rotuladora 40 & 27,80 & 27,80 & 18,69 & 18,69 \\
\hline Rotuladora 42 & 9,00 & 9,00 & 6,05 & 6,05 \\
\hline T. Diluição** & 23,73 & --- & --- & 23,73 \\
\hline Cor. sala máq. & 3,58 & 3,58 & 2,41 & 2,41 \\
\hline F. Abrand.**. & 87,30 & --- & -- & $\mathbf{1 . 9 6 1 , 3 2}$ \\
\hline Total (m $\left.{ }^{\mathbf{3}}\right)$ & & & & \\
\hline
\end{tabular}

Fonte: Dados da pesquisa

Notas: (*) pontos de fornecimento de água passíveis de redução. (**) setores não passíveis de redução.

Comparando-se o valor total de consumo para o período, que é de $2.054,23 \mathrm{~m}^{3}$, e a redução deste consumo para $1.961,32 \mathrm{~m}^{3}$, pode-se estabelecer um cenário de diminuição da utilização do recurso hídrico, implicando na economia de energia elétrica utilizada na captação de água dos poços (que é feita por meio de bombas), uma redução na geração de efluentes e, consequentemente, um maior controle da poluição das águas, acarretando também em um menor custo de operação do sistema de tratamento de efluentes da empresa. Portanto, o novo valor de IA que pode ser obtido a partir desta proposta é apresentado na tabela 7.

Tabela 7: Cenário de redução no consumo do recurso hídrico.

\begin{tabular}{|c|c|c|c|}
\hline $\begin{array}{c}\text { Volume gerado sem } \\
\text { redução }(\mathbf{m})\end{array}$ & $\begin{array}{c}\text { Volume gerado com } \\
\text { redução }\left(\mathbf{m}^{3}\right)\end{array}$ & $\begin{array}{c}\text { Porcentagem de } \\
\text { redução }(\%)\end{array}$ & $\begin{array}{c}\text { Indice de consumo } \\
\text { com a redução }\end{array}$ \\
\hline
\end{tabular}




\begin{tabular}{|l|l|l|l|}
\hline $2.054,23$ & $1.961,32$ & 4,52 & 2,109 \\
\hline
\end{tabular}

Fonte: Dados da pesquisa

Observa-se que houve uma redução no indicador ambiental da ordem de 2,59\%, representado uma economia significativa de água de, aproximadamente, $92,91 \mathrm{~m}^{3}$ de água num período de 12 dias.

Assim, tem-se uma vazão de efluente da ordem de: $1.961,32 \mathrm{~m}^{3} / 88$ horas $=22,29 \mathrm{~m}^{3} / \mathrm{h}$ implicando em uma redução média na geração de efluentes de 4,52\%, como fica evidenciado na tabela 7. Isto significa que 92.910 litros de água deixariam de ser contaminados e enviados ao sistema de tratamento de águas residuárias da empresa, diminuindo a pressão sobre o sistema.

\section{- Cenário 2: Reuso da água de lavagem das lavadoras de recipientes}

Como foi visto no item referente ao cálculo da produção média de efluente e consumo de água, a limpeza dos recipientes de envase nas lavadoras responde pelo maior consumo de água nos processos de limpeza. O efluente gerado nesta etapa apresenta condições de reuso para a limpeza de piso, esteiras e, até mesmo, das próprias lavadoras. Neste segundo cenário de reuso, propõe-se a utilização da água de lavagem das lavadoras 70,40 e 42 para a limpeza dos setores em que estas lavadoras estão alocadas.

A geração total de efluente no período, para as três lavadoras, é de $909,12 \mathrm{~m}^{3}$ e considerando a demanda para os setores onde se localizam as lavadoras tem-se, na tabela 8 , o percentual do volume total gerado, reutilizado.

Tabela 8: Demanda de água para a limpeza e porcentagem de reuso.

\begin{tabular}{|c|c|c|}
\hline Setor & Demanda de água $\left(\mathbf{m}^{3}\right)$ & Proporção de reuso (\%) \\
\hline Lavadora 70 e $40^{*}$ & 268,46 & 29,53 \\
\hline Lavadora 42* & 9,00 & 0,99 \\
\hline Totais & $\mathbf{2 7 7 , 4 6}$ & $\mathbf{3 0 , 5 2}$ \\
\hline
\end{tabular}

Fonte: Dados da pesquisa

Nota: $(*)$ incluindo esteiras, piso, rotuladora e encaixotadora.

Do total disponível de 909,12 $\mathrm{m}^{3}$, pode-se utilizar cerca de 30\% desta água nos processos de limpeza nos locais em que se localizam as lavadoras; portanto, o valor do Indicador Ambiental para este caso de reuso parcial da água é estabelecido segundo a tabela 9.

Tabela 9: Cenário de reuso parcial da água de lavagem das lavadoras.

\begin{tabular}{|c|c|c|}
\hline Volume sem reuso $\left(\mathbf{m}^{\mathbf{3}}\right)$ & Volume com reuso $\left.\mathbf{( m}^{\mathbf{3}}\right)$ & Indicador ambiental \\
\hline $2.054,23$ & $1.776,68$ & 1,997 \\
\hline
\end{tabular}

Fonte: Dados da pesquisa

Há uma redução de 7,76\% no Indicador Ambiental, o que mais uma vez traz benefícios, principalmente, em relação à conservação dos recursos hídricos que deixarão de ser poluídos. Em termos de processos industriais, esta redução no indicador expressa um aumento na eficiência e uma maximização no uso de insumos.

Relacionando esta diminuição no IA com a vazão de efluente no sistema de tratamento, percebe-se que esta fica ainda mais reduzida: $1.776,68 \mathrm{~m}^{3} / 88$ horas $=20,19 \mathrm{~m}^{3} / \mathrm{h}$. Ou seja, cerca de 277 mil litros de água deixariam de ser utilizados.

\section{- Cenário 3: Redução no consumo de água aliada ao reuso parcial da água proveniente da lavagem das lavadoras}


Pode-se somar ao efeito do reuso, a redução do consumo avaliada anteriormente o que, como mostra a tabela 10, implica em uma redução ainda maior do indicador ambiental e, consequentemente, um aumento da eficiência dos processos.

Tabela 10: Cenário de reuso parcial e redução de consumo.

\begin{tabular}{|l|l|l|}
\hline Volume sem reuso $\left(\mathbf{m}^{\mathbf{3}}\right)$ & Volume com reuso $\left(\mathbf{m}^{\mathbf{3}}\right)$ & Indicador ambiental \\
\hline $1.961,32$ & $1.683,77$ & 1,941 \\
\hline
\end{tabular}

Fonte: Dados da pesquisa

A redução no indicador ambiental é ainda maior neste cenário de reuso parcial e redução de consumo, representando um aumento na eficiência de $10,35 \%$, se comparada à eficiência no cenário inicial.

Há consequências também na geração de efluentes que seria de: 1.683,77 / 88 horas $=19,13$ $\mathrm{m}^{3} / \mathrm{h}$, isto é, uma redução de $18,04 \%$; indicando que, no período, cerca de $370 \mathrm{~m}^{3}$ de água deixaria de ser poluída, o que diminuiria drasticamente a pressão sobre o sistema de tratamento de água residuárias da empresa.

\section{- Cenário 4: Reutilização total da água de lavagem e redução de consumo}

Por fim, traçando um cenário ideal de redução e reutilização total da água de lavagem das lavadoras, poderia ser feita a aplicação desta água de reuso em todas as unidades produtivas da empresa e também em banheiros, área de carga e descarga de lotes do produto final, limpeza de caminhões de transporte e oficina.

Para assegurar a segurança sanitária e evitar contaminações por microrganismos e substâncias tóxicas, teriam que ser realizadas regularmente análises bacteriológicas e de identificação de compostos para se garantir a qualidade da água de reuso, sobretudo para aquela que seria encaminhada aos processos que implicariam no contato direto com tanques, tubulações, bombas ou equipamentos envolvidos na produção do refrigerante.

Este cenário ideal é apresentado na tabela 11.

Tabela 11: Cenário ideal de reuso e redução de consumo.

\begin{tabular}{|c|c|c|c|}
\hline $\begin{array}{c}\text { Demanda de água } \\
\text { na limpeza }\left(\mathbf{m}^{\mathbf{3}}\right)^{*}\end{array}$ & $\begin{array}{c}\text { Volume total de } \\
\text { água de reuso }\left(\mathbf{m}^{\mathbf{3}}\right)\end{array}$ & $\begin{array}{c}\text { Efluente gerado no } \\
\text { reuso }\left(\mathbf{m}^{\mathbf{3}}\right)\end{array}$ & Indicador ambiental \\
\hline $1.052,20$ & 909,12 & $1.052,20$ & 1,559 \\
\hline
\end{tabular}

Fonte: Dados da pesquisa

Nota: $(*)$ exceto efluente gerado pelas lavadoras.

Observando a tabela 11, percebe-se que, neste quarto cenário, a demanda de água para a limpeza é igual ao volume de efluente gerado no reuso para o período. Isto só ocorre porque se passou a considerar o efluente produzido na lavagem dos recipientes de envase, totalizando assim um volume de 1.052,20 $\mathrm{m}^{3}$ e não mais $909,12 \mathrm{~m}^{3}$ de efluente. Assim, toda a água de lavagem seria reutilizada, tendo seu volume incorporado ao efluente gerado na limpeza.

Por fim, pode ser percebida uma grande redução no indicador ambiental, da ordem de $27,99 \%$, o que indica um significativo aumento da eficiência dos processos de limpeza. O IA para este cenário, no valor de 1,559, expressa, além da grande eficiência, uma maximização no uso do recurso hídrico e uma economia em insumos, energia elétrica e na diminuição no desgaste de equipamentos.

Comparando-se o cenário inicial de uso atual do recurso hídrico com este cenário ideal (tabela 12), percebe-se a dimensão da economia e do volume de água que deixaria de ser utilizada e contaminada.

Tabela 1: Comparação entre o cenário atual e o ideal.

\begin{tabular}{|l|c|c|c|} 
Cenário & Geração de efluente $\left(\mathbf{m}^{3}\right)$ & Vazão de efluente & Volume de água não \\
\hline
\end{tabular}




\begin{tabular}{|c|c|c|c|}
\hline & & $\left(\mathbf{m}^{\mathbf{3}} \mathbf{h}\right)$ & contaminada $\left(\mathbf{m}^{\mathbf{3}}\right)$ \\
\hline Atual & $2.054,23$ & 23,34 & 0,00 \\
\hline Ideal & $1.052,20$ & 11,96 & $1.001,44^{*}$ \\
\hline
\end{tabular}

Fonte: Dados da pesquisa

Nota: $(*)$ reuso da água de lavagem das lavadoras mais a redução no consumo.

Portanto, mais de 1 milhão de litros de água deixariam de ser poluídos e o aumento da eficiência do sistema, expresso pelo indicador ambiental, configuraria na consolidação de um sistema de gestão ambiental para o recurso hídrico.

Comparando-se os cenários apresentados com a situação atual têm-se, na figura 3, representadas as diferenças de consumo de água total para cada um dos cenários descritos acima.

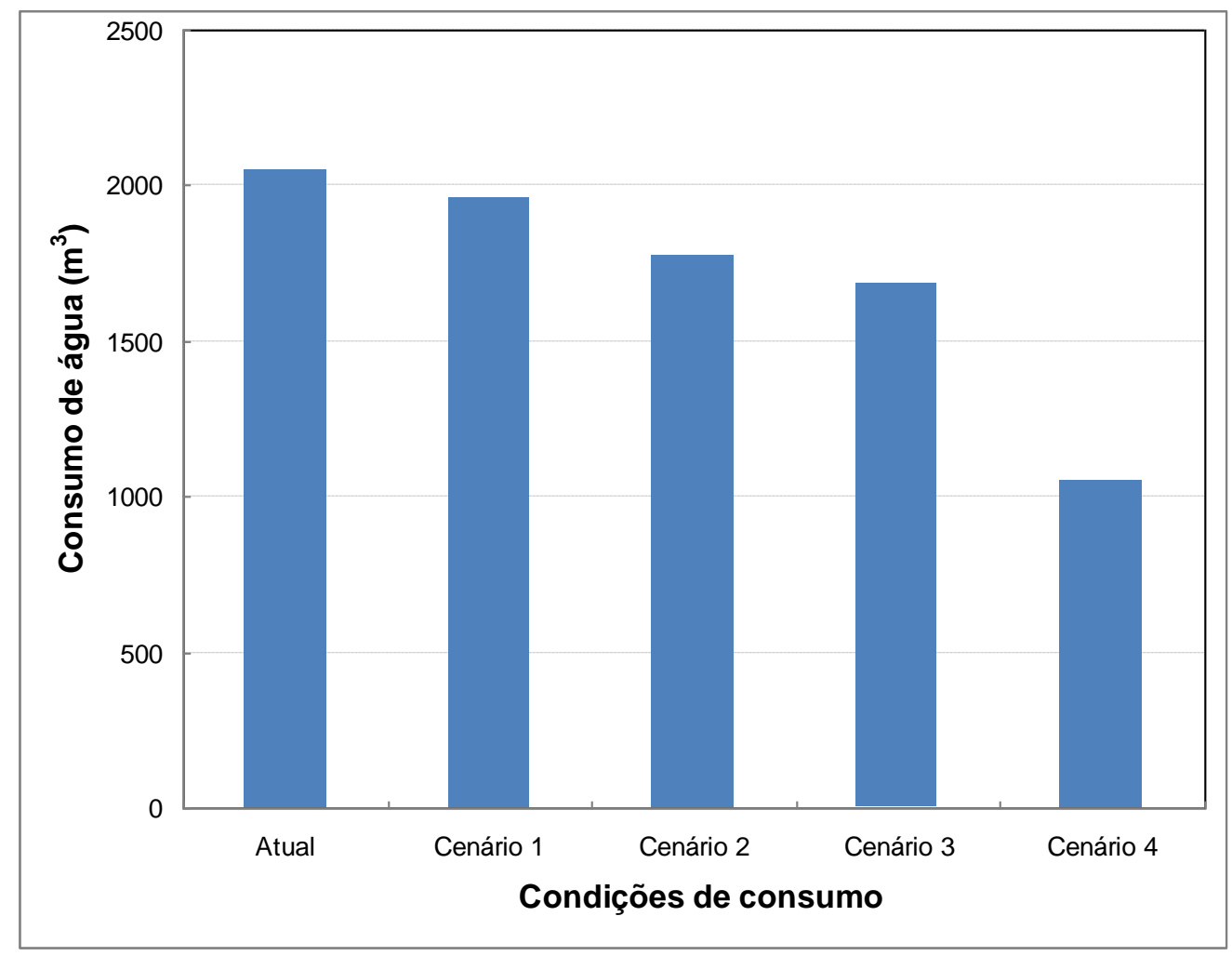

Figura 3: Comparação do consumo de água entre os cenários.

Fonte: Dados da pesquisa

\section{CONSIDERAÇÕES FINAIS}

Sobre o aspecto ambiental mais relevante pertinente às atividades da empresa, ou seja, o consumo de água, pôde-se, por meio do diagnóstico, quantificar as entradas e saídas de recursos hídricos nos processos produtivos, originando um balanço de massa para a água.

Por meio deste balanço, construiu-se o Indicador Ambiental, expresso, no diagnóstico, pelo valor de 2,165 litros de água para cada litro de produto final, correspondendo a uma geração média de efluente da ordem de $23,34 \mathrm{~m}^{3} / \mathrm{h}$, o equivalente a um volume de $2.054,23 \mathrm{~m}^{3}$ gerado no período de 12 dias. Pelas variações deste indicador, em consequência dos diferentes cenários apresentados, foi possível avaliar os benefícios ambientais e econômicos advindos da aplicação das propostas de redução e reuso. 
No primeiro cenário, de redução de consumo, por meio das observações de campo, chegouse a uma taxa média de redução do valor do IA de $2,59 \%$, o que evitaria a poluição, no período, de cerca de 92 mil litros de água.

Já no segundo cenário, no qual se propõe o reuso da água despendida na limpeza dos recipientes de envase nas lavadoras para a higienização do piso, esteiras e até mesmo das próprias lavadoras; o Indicador Ambiental passaria a ser 1,997, ou seja, haveria uma redução de 7,76\% em relação ao valor inicial e isto significa deixar de poluir 277 mil litros de água.

Combinando os cenários de redução e reuso da água de lavagem das lavadoras, os resultados são ainda mais satisfatórios, baixando o Indicador Ambiental para 1,941 litros de água para cada litro de produto final e evitando-se que mais de 370 mil litros de água sejam poluídos.

Ainda, em um último cenário, o indicador chegou a um valor ainda mais baixo, ou seja, $(1,559)$ representando uma redução de $27,99 \%$ do consumo de água, sendo equivalente à eficiência de grandes corporações do ramo de refrigerantes. Os benefícios ambientais também cresceriam na mesma proporção, chegando-se a uma vazão média de efluente na ordem de $12 \mathrm{~m} / \mathrm{h}$ e evitando-se a poluição de cerca de 1 milhão de litros de água, o que significaria uma economia de cerca de 3 milhões de litros por mês.

Ressalta-se também que este indicador permite que a empresa estabeleça futuras metas ambientais e que sejam feitas avaliações que determinem o progresso da organização em relação à gestão das águas. Portanto, tendo como base as variações no valor IA, se buscará o cumprimento de tais metas, não restringindo a produção, mas sim aliando a esta, ações práticas de minimização do uso deste recurso; consolidando assim, uma visão socioambiental às perspectivas produtivas da empresa.

\section{REFERÊNCIAS}

Andrade, R. O. B., Tachizawa, T. E Carvalho, A. B. (2002) Gestão ambiental: enfoque estratégico aplicado ao desenvolvimento sustentável. (2 ${ }^{\mathrm{a}}$ ed.) São Paulo: Makron Books.

Associação Brasileira De Normas Técnicas (2004) NBR ISO 14.001. Sistemas da gestão ambiental - Requisitos com orientação para uso. Rio de Janeiro: ABNT.

Associação Brasileira das Indústrias de Refrigerantes e bebidas não-alcoólicas - Abir. Recuperado em 15 de agosto de 2009, de www.abir.org.br/.

Associação dos Fabricantes de Bebidas do Brasil - Afrebras. Recuperado em 10 de agosto de 2009, de //www.afrebras.org.br/refrigerante.ph.

Campos, H. M., Oliveira, L. H. (2004) Estratégias da indústria de refrigerantes: um estudo sobre as "Tubaínas". In: Encontro Científico da CNEC, 2, Varginha, 2004. Recuperado em 25 de setembro de 2009, de://www.administradores.com.br.

Comissão Empresarial para Reciclagem - Cempre (2008). O mercado para reciclagem. São Paulo. Recuperado em 16 de setembro de 2009, de://www.cempre.org.br/.

Instituto Coca-Cola. Prêmio por um país melhor: reaproveitamento de água de processo. Jundiaí. 21 slides, color. Recuperado em 01 de novembro de 2009, de http://www.institutococacolabrasil.org.br/FEMSA.

Moura, L. A. A. (2002) Qualidade e gestão ambiental. (3 ${ }^{\mathrm{a}}$ ed). São Paulo: Juarez de Oliveira. 
Serviço Nacional De Aprendizagem Industrial - Senai. Recuperado em 15 de agosto de 2009, de do http://www.senai.br/br/home/index.aspx.

Viterbo Júnior, E. (1998) Sistema integrado de gestão ambiental: como implementar um sistema de gestão que atenda a norma ISO 14001, a partir de um sistema baseado na norma ISO 9000. (2a ed.) São Paulo: Aquariana.

Xavier, A. P. S. (2003) Gestão ambiental como vantagem competitiva em indústrias de bebidas: estudo de três casos em Fortaleza. 147 folhas. Dissertação (Mestrado em Administração de Empresas) - Universidade de Fortaleza, Fortaleza/CE, Brasil.

Data do recebimento do artigo: 07/09/2010

Data do aceite de publicação: 02/08/2011 